\title{
A mentalidade censória de Rogério Nunes tematizada no jornalismo impresso dos anos $1970^{1}$
}

\author{
Guilherme Moreira Fernandes' \\ https://orcid.org/0000-0001-6896-4963
}

\section{Karina Janz Woitowicz"}

https://orcid.org/0000-0002-7644-8560

I - Universidade Federal do Recôncavo da Bahia.

Cachoeira (BA). Brasil.

II - Universidade Estadual de Ponta Grossa.

Ponta Grossa (PR). Brasil.

Resumo: O presente artigo tem como objetivo analisar as narrativas sobre a censura às diversões públicas materializadas na atuação de Rogério Nunes, que ocupou a chefia de Divisão de Censura de Diversões Públicas (DCDP) entre os anos de 1971 a 1979, durante a ditadura militar no Brasil. A partir da noção de mentalidade expressa por Vovelle (1991), foi realizada uma pesquisa empírica em acervos de jornais de grande circulação publicados no período, de modo a identificar o tratamento dado ao censor e à prática da censura, e perceber marcas ideológicas que repercutem valores morais vigentes na época.

Palavras-chave: censura; jornalismo impresso; televisão; ditadura militar.

1 O presente artigo tem como base a pesquisa de doutorado de Guilherme Moreira Fernandes (2018), que teve continuidade durante o estágio pós-doutoral, realizado pelo autor no Programa de PósGraduação em Jornalismo da Universidade Estadual de Ponta Grossa, sob a supervisão de Karina Janz Woitowicz. Uma versão preliminar do trabalho pode ser conferida em Fernandes (2018b), e algumas referências parciais podem ser encontradas em outros textos que possuem relação com a temática, além da base teórico-metodológica do artigo. Ver: Fernandes (2018c, 2019) 


\begin{abstract}
The censorial mentalité of Rogério Nunes themed in 1970's printed journalism - This paper aims to analyze the narratives about the censorship of public diversions materialized in the performance of Rogério Nunes, who served as head of the Public Diversity Censorship Division (DCDP) between 1971 and 1979, during the military dictatorship in Brazil. Based on the notion of 'mentalité' expressed by Vovelle (1991), empirical research was carried out on collections of widely circulated newspapers published in the period, in order to identify the treatment given to the censor and the practice of censorship as well as to perceive ideological marks that reflect moral values prevailing at the time.
\end{abstract}

Keywords: censorship; printed journalism; TV; military dictatorship.

\title{
Introdução
}

A censura às diversões públicas no Brasil tem origem ainda no período colonial e permanece presente até a promulgação da Constituição de 1988 (CARNEIRO, 2002). Inscrita no tempo de longa duração (praticamente 500 anos), a censura se materializa a partir de dispositivos legais executados dentro de uma estrutura burocrática do governo com competência para tal. Martins (2002) aponta que as formas de repressão, entre elas a censura, têm uma origem comum que está ligada à herança colonial, à necessidade de um Estado forte e às noções de moralidade da Igreja Católica.

A historicidade das ações censórias em um tempo histórico revela continuidades, sobretudo na proteção e promoção da moral e dos bons costumes². Embora em cada tempo e espaço as noções de moralidade podem emergir, a atividade censória é por natureza mais rígida que o conjunto da sociedade. A doutrina de Mello Barreto Filho (1941) estabelece que, no âmbito legal, as diversões públicas são aquelas acessíveis à população realizadas em lugares abertos ou fechados. São considerados locais de diversões públicas os

2 Neste texto nos valemos da acepção de moral de Foucault (1984). O filósofo percebe uma ambiguidade da palavra moral, que pode ser dividida em dois fenômenos: "código moral" e "moralidade dos comportamentos". Por um lado, a moral pode ser entendida como "conjunto de valores e regras de ação propostas aos indivíduos e aos grupos por intermédio de aparelhos prescritivos diversos, como podem ser a família, as instituições educativas, as Igrejas, etc" (FOUCAULT, 1984, p. 33). Por outro, o pensador admite que essas regras e valores tanto podem ser formuladas em uma doutrina coerente e um ensinamento explícito, como também podem ser transmitidas de maneira difusa com elementos, inclusive, antagônicos. Esse conjunto prescritivo de moral é chamado por ele de "código moral". Concomitantemente, a moral também pode ser entendida como "o comportamento real dos indivíduos em relação às regras e valores que lhes são propostos" (FOUCAULT, 1984, p. 33), sendo este fenômeno a "moralidade dos comportamentos". Além dessas duas formas, Foucault ainda admite uma terceira via, que é a "maneira pela qual se deve constituir a si mesmo como sujeito moral, agindo em referência aos elementos prescritivos que constituem o código" (FOUCAULT, 1984, p. 34). Sendo assim, coexistem a regra, o comportamento e o sujeito moralizador. 
teatros, cinemas, circos, arenas, dancings, etc., além dos meios de comunicação — no aspecto não noticioso - como rádio e, posteriormente, a televisão.

Com exceção do período que compreende a ditadura varguista (1939 - 1945), em que esteve vigente o Departamento de Imprensa e Propaganda (DIP), ao longo do período republicano a censura de diversões públicas esteve a cargo da Polícia Federal, subordinada ao Ministério da Justiça. As ações censórias sofriam variações conforme a visão dos dirigentes do processo, embora as estruturas formem mentalidades que perpassam um tempo de longa duração. A legislação censória revela continuidades com poucas rupturas, sendo a incorporação da tecnologia o principal motivo para a modificação legal. Ademais, doutrinas como a da segurança nacional ${ }^{3}$ e reformas administrativas eram comumente incorporadas na atividade legal. O fenômeno jurídico é social e procura estar atento ao "espírito do tempo" ou "mentalidade coletiva" de cada época.

No caso brasileiro, o patrimonialismo e demais valores conservadores (monogamia, religiosidade católica, desigualdade entre sexos, naturalização da inferioridade de grupos populares, etc.) são peças-chave que vão mover a atividade censória e expressar a mentalidade. No âmbito desse texto, a base legal foi regulada pelo Decreto $n^{\circ} 20$ 493, de janeiro de 19464, que aprova a instalação do Serviço de Censura de Diversões Públicas do Departamento de Polícia Federal (SCDP/DPF). A reforma administrativa do DPF ${ }^{5}$, em 1972, renomeou a estrutura para Divisão de Censura de Diversões Públicas (DCDP), mantendo o regulamento aprovado no início da república populista (4ª república) em atendimento aos preceitos da Constituição que seria promulgada em setembro daquele ano. Nota-se que a principal base legal é anterior à inauguração oficial da televisão no Brasil, embora a lei mencione que o veículo seria objeto da censura.

A operação que realizamos parte da noção da história das mentalidades, que "situa-se no ponto de junção do individual e do coletivo, do longo tempo e do quotidiano, do inconsciente e do intencional, do estrutural e do conjuntural, do marginal e do geral" (LE GOFF, 1988, p. 71). Para Vovelle (1991), na mentalidade há de se considerar uma "história das visões de mundo", na

3 Uma interpretação, aplicada à televisão, da Escola Superior de Guerra e a elaboração da doutrina de Segurança Nacional está em Mattos (2010). A aplicação por parte dos censores é detalhada por Fagundes (1974).

4 O conjunto de leis aqui referenciadas estão reunidas em Fagundes (1974).

5 Decreto n. 70.665, de 2 de junho 1972. 
qual está inserida a questão da ideologia. Segundo o autor, as mentalidades são marcadas por motivações inconscientes e remetem à memória e aos gestos de resistência (VOVELLE, 1991, p.14-20).

Ao considerar as mentalidades, é possível aceder e interpretar atitudes e representações coletivas, configurando não apenas o estudo de condições objetivas, mas também a forma como os grupos veem e narram sua própria história, fazendo, desta forma, a construção de sentidos. É a partir de Vovelle que pensamos em "mentalidade censória" nos dispositivos e se materializa em atos e ações de censura. A presença de mentalidades censórias não exclui as possíveis diferenças de intensidades censórias por diversas razões como individualidade, direcionamento político, predisposição e posições políticas além das normas, diretrizes e posturas.

Neste artigo propomos apresentar um dos dirigentes do processo censório em ação durante o regime autoritário. Rogério Nunes foi o dirigente do SCDP/ DCDP que permaneceu mais tempo no cargo. Nos valemos da concepção do jornalismo como fonte de conhecimento e de pesquisa histórica (PARK, 1970; BARBOSA, 2007) para buscarmos as materialidades e intencionalidades tematizadas a partir do jornalismo impresso. Interessa-nos a fala proferida nos diversos momentos em que a história estava sendo construída, perfazendo certo conjunto de tempo (neste caso o período em que ocupou o referido cargo). Ao nos depararmos com um conjunto de "falas", apuradas nos jornais, a preocupação passa a ser a interpretação (BARBOSA, 2007; 2010) que compreende as razões e sentidos presentes nos textos.

Para a realização da pesquisa, foi utilizada a plataforma da Hemeroteca Digital da Biblioteca Nacional7. Também foi consultado, como recurso adicional, o acervo digital, hospedado em portais de outros jornais e revista de circulação nacional, a saber: 0 Globo ${ }^{8}$, Folha de S. Paulo ${ }^{9}$, O Estado de S. Paulo $^{10}$ e Veja ${ }^{11}$. Embora nem todos os veículos sejam citados no presente artigo, é importante considerar que fazem parte de um cenário de produção jornalística marcado pela convivência com a censura, que ocupa direta

6 Usamos o plural (mentalidades censórias) para nos referirmos à herança de longa duração e o singular (mentalidade censória) quando há uma personificação dos atos e ações.

7 Disponível em: http://bndigital.bn.gov.br/hemeroteca-digital/.

8 Disponível em: http://acervo.oglobo.globo.com/.

9 Disponível em: https://acervo.folha.com.br/index.do.

10 Disponível em: http://acervo.estadao.com.br/.

11 Disponível em: https://acervo.veja.abril.com.br/. 
ou indiretamente suas páginas ${ }^{12}$. A pesquisa documental foi feita a partir da busca pela palavra-chave "Rogério Nunes" e na sequência abrimos todas as ocorrências geradas pela Hemeroteca Digital. A seleção do material teve como critério a presença de aspas do Diretor, retratando a censura à televisão e especificamente à telenovela, entendido aqui como o principal produto da indústria cultural brasileira. Utilizamos a análise documental como técnica e método (MOREIRA, 2006) para interpretar as falas de Nunes e perceber nelas elementos balizadores da mentalidade. Organizamos as falas em ordem cronológica e posteriormente selecionamos trechos que julgamos ser os mais representativos da sua gestão.

Entendendo o jornalismo como documento privilegiado para a percepção histórica, nos centramos em perguntas específicas direcionadas ao modo como o jornalismo apresentou o censor e as marcas das mentalidades censórias em seu discurso na imprensa. ${ }^{13} \mathrm{~A}$ análise concentra-se nos depoimentos em torno da censura às diversões públicas presentes nos textos, que permitem posicionar os jornais como porta-vozes dos agentes da ditadura, bem como identificar argumentos polêmicos diluídos ao longo da narrativa. Assim, o jornalismo é interpretado como um conjunto de discursos que provocam sentidos e manifestam relações com a sociedade e os poderes da época.

\section{A censura às Diversões Públicas na figura de Rogério Nunes}

Para compreender o cenário de que se fala, é importante reconhecer a existência de três instâncias hierárquicas: o Ministro da Justiça, a chefia da Polícia Federal e a chefia do serviço/divisão de censura. O SCDP/DCDP tinha um dirigente geral, que, por vezes, se dirigia à imprensa para expressar e justificar suas ações coletivas. Em um período considerado de forte repressão política ${ }^{14}$, Rogério Nunes foi o chefe que permaneceu mais tempo no cargo

12 A censura à imprensa é apenas uma das variantes para pensar a produção jornalística. Smith (2000) sustenta a tese de que havia um consentimento da imprensa com as ações censórias e, logo, com as políticas do governo. Há diversas pesquisas (MARCONI, 1980; AQUINO, 1999) que demostram o exercício autoritário do Estado em relação à imprensa, o que seria nos dizeres de Marconi (1980) a manifestação da "psicose da Segurança Nacional". Ademais da censura à imprensa, outros aspectos do jornalismo, com as rotinas, a estrutura e a visão organizacional, possibilitam reflexões acerca das formas de controle da informação.

13 A inspiração metodológica para a elaboração das perguntas adveio da pesquisa de Barbosa (2010), que leva em consideração a noção de campo como espaço de luta simbólica marcado por um determinado habitus, como preconiza Bourdieu.

14 A ditadura militar brasileira tem, no ano de 1968 um importante marco para sua legitimação, com o fechamento completo do sistema político e a implementação do Ato Institucional $n^{\circ} 5$ (Al-5). Rogério Nunes atuou no governo Médici (1969-1974) e no governo Geisel (1974-1979), acompanhando um período de forte repressão, controle do Estado e o prenúncio da reabertura política, no final dos anos 1970. 
e apresentou posição rígida em relação à censura da telenovela, com a proibição da sinopse das telenovelas "Roque Santeiro" (1975) e "Despedida de Casado" (1976), mesmo após a aprovação. De acordo com Fernandes (2018c),

Nunes foi o mais longevo chefe da censura federal, permanecendo sete anos no cargo, de novembro de 1971 a março de 1979. Chegou a trabalhar diretamente com três diretores da Polícia Federal: Gen. Bgda. Nilo Caneppa, Gen. Bgda. Antônio Bandeira e Cel. Moacyr Coelho; e com dois Ministros da Justiça, Alfredo Buzaid e Armando Falcão. Durante o tempo em que esteve no cargo, Nunes não passou por nenhuma modificação legislativa, embora diversos projetos tenham sido estudados durante o período. No âmbito da censura à telenovela, foi o mais rígido de todos. (FERNANDES, 2018c, p. 05).

Nunes se mostrou ferino à TV como veículo de comunicação massiva, na justificativa de que, de forma diferente às demais diversões públicas, a TV entra na casa das pessoas. Deve-se considerar também que o próprio Regime Militar contribuiu para a expansão da TV em um projeto de integração territorial via comunicação (MATTOS, 2010). No entanto, vozes que eram interpretadas como subversivas e contrárias à moralidade católica eram eliminadas e impedidas de ir ao ar.

Além do longo tempo como responsável pela divisão de censura e pela reestruturação administrativa do órgão, outro aspecto importante foi o fato de Nunes ser um policial federal de carreira. Embora não tivesse trabalhado especificamente como censor, foi o primeiro funcionário do DPF a ocupar o cargo, fato noticiado pelo jornalismo da época.

O novo chefe do Serviço de Censura Federal será o Sr. Rogério Nunes, um policial de carreira que vem exercendo há um ano a chefia da Delegacia Regional de Polícia Federal em Brasília, onde se destacou, principalmente, pelo seu combate aos traficantes de tóxicos da cidade. Ele substituirá na censura o inspetor de polícia Geová Cavalcante, que vinha exercendo o cargo há um ano. O Sr. Rogério Nunes é apontado por seus companheiros como um dos responsáveis pela adoção, em caráter experimental, de uma nova estrutura administrativa para uma Delegacia Regional, de modo a tornar o seu funcionamento mais eficiente e dinâmico. Formado pela Faculdade de Direito do Estado do Rio, o sr. Rogério Nunes é policial há 34 anos. Começou como guarda civil. Depois foi corregedor da Polícia Federal, diretor da Polícia Federal de Investigações, e chefe de gabinete do 
diretor-geral do DPF. A sua indicação para a chefia da censura faz parte também do interesse do General Nilo Caneppa em nomear para altas funções no órgão funcionários da casa para valorizá-los. (JORNAL DO BRASIL, 23 out 1971, p. 3).

Como é possível verificar na matéria do Jornal do Brasil, ao apresentar o currículo profissional de Rogério Nunes, o texto o destaca como bom gestor e, além disso, o classifica como severo e até mesmo intransigente, com certo tom elogioso. As habilidades do censor e seu rigor no tratamento das diversões públicas, especialmente ligadas à televisão, serão o foco de atenção dos jornais durante sua gestão, de modo a evidenciar controvérsias e explicações sobre o papel da censura durante o governo autoritário.

\title{
A censura às diversões públicas repercutida nos jornais
}

O cumprimento das normas censórias se apresenta de forma rígida durante a administração de Rogério Nunes, especialmente na fase ligada ao governo Geisel, em que chegou a proibir telenovelas já liberadas. De acordo com Fernandes (2018b, p. 223),

\begin{abstract}
Ademais, ele chegou a modificar a grade de programação das emissoras de TV com a reclassificação etária. O teatro e o cinema também sofreram grande repressão no momento em que ele esteve à frente do cargo, conforme nota do Diário de Pernambuco: "Os artistas de teatro fizeram um levantamento e chegaram a seguinte conclusão: nos últimos cinco anos foram censuradas mais peças do que em todo o período da República brasileira. Alarmados, encaminharão manifesto ao presidente Ernesto Geisel" (DIÁRIO DE PERNAMBUCO, 30 ago 1975, p. 9).
\end{abstract}

A posse de Rogério Nunes aconteceu no dia 4 de novembro de 1971 em sessão reservada, conforme registrado pelos jornais da época, e desde então tomou para si a missão de endurecer a censura à televisão:

O diretor da Divisão de Censura, Rogério Nunes, explicou ontem que os programas de televisão têm que ser submetidos a um rigoroso exame antes de serem liberados, de vez que não há possibilidade de controlar a audiência "pois a TV entra na casa de todo mundo sem pedir licença". Com relação à novela Roque Santeiro, que faria sua estreia ontem na Rede Globo, acentuou que a censura utilizou 
os critérios de rotina e nada de especial houve $\mathrm{e}^{15}$. Os cortes determinados devem ser feitos e a novela não poderá ser exibida antes das 22 horas. $O$ diretor da Censura reiterou o que em muitas oportunidades já havia acentuado no sentido de que a televisão merece um cuidado especial de vez que ninguém controla a audiência. [...] No caso de Roque Santeiro, explicou que os cortes se referem às cenas que mostravam uma casa de mulheres e que, por isso, não poderiam ser vistas por menores. (JORNAL DO BRASIL, 28 ago 1975, p. 14).

A censura, "sem ter sido", à "Roque Santeiro", foi um dos maiores feitos de Rogério Nunes. O censor demonstrava especial atenção aos veículos de comunicação de massa como a televisão e o rádio, para os quais declarava a necessidade de um maior controle e rigor . Isso porque, para ele, o fato de existir uma indicação de faixa etária adequada ao horário de exibição não impedia que alguém de pouca idade também assistisse à TV, uma vez que ela "entra na casa das pessoas". Nas outras diversões (teatro e cinema), o cumprimento da diretriz censória se mostrava mais efetivo. O Estado se preocupava com a não obediência da norma etária presumida, o que parece justificar, em nome da "moral e dos bons costumes", a censura aos diversos tipos de produção cultural.

Ao fazer o balanço da censura no ano seguinte (1976), Rogério Nunes continuava a evidenciar o exercício da censura televisiva.

"Há também doentes que detestam os médicos", disse ontem o diretor da Divisão de Censura de Diversões Públicas do Departamento de Polícia Federal, Rogério Nunes, ao ser indagado das razões para os intelectuais detestarem a Censura, que considerou "liberal e adequada à nossa sociedade, porque os conceitos de moral mudam no tempo e no espaço". Ao fazer um balanço da ação da Censura neste ano, o Sr. Rogério Nunes mostrou que houve menos livros, filmes e novelas proibidos do que em 1975. E se preocupou em justificar o veto à Despedida de Casado, novela da Rede Globo, e de lembrar que os critérios só mudarão com a nova legislação, em preparo pelo Ministério da Justiça. “O que há é um grande erro de interpretação sobre o que seja censura: vocês (repórteres) acham que é o veto, mas é o exame do espetáculo para estabelecer uma classificação etária". [...] Quanto

15 O processo de censura a "Roque Santeiro" foi analisado por Fernandes (2018). Embora para o autor a emissora tenha entendido que a DCDP não iria permitir a liberação da telenovela, os documentos censórios não demonstram uma proibição total da veiculação do folhetim, constando "apenas" a indicação que a trama não poderia ser exibida às $20 \mathrm{~h}$. 
à proibição de Despedida de Casado, o sr. Rogério Nunes disse que o amor livre, ou tudo que se possa redundar em dissolução do casamento, não se permite apresentar na televisão. Afirmou que foi liberado o resumo, mas o veto tornou-se imperioso ao se examinar os textos completos e o material gravado. [...]. O diretor da DCDP entende que será necessário enviar à Censura os textos completos, com a gravação, para que se possa ter uma ideia geral do espetáculo e haja condições de decidir sobre a liberação. Afirmou ainda que "a censura é institucionalizada em 150 países. Ela sempre existiu e deve existir para evitar os excessos. Ela surge desde o ambiente familiar". Apesar de afirmar que a censura é adequada à nossa sociedade, o sr. Rogério Nunes dedicou boa parte do balanço à Consolidação das Leis de Censura, trabaIho do Ministério da Justiça para atualizar critérios em vigor há 30 anos. No seu entender, a grande atualização é enquadrar a televisão na legislação, "pois é onde há os maiores problemas: a televisão é um dos meios de comunicação que merece cuidado muito especial porque ele entra no lar sem pedir licença, a TV não tem porteiro". [...] O sr. Rogério Nunes acha que a censura conta com pessoal qualificado em número suficiente, e observou: "Nas decisões não se visa o autor, mas a obra. O artista e a sua obra não são imunes. Se ele ultrapassar, será punido, porque ele não tem imunidade perante a lei. Ninguém proíbe ninguém". A Censura ainda examinou 2070 capítulos de telenovelas e 1424 de radionovelas, além de 64 gravações de espetáculos de TV. [...]. Concedeu registro para 178 novas revistas e examinou 148 para divulgação (JORNAL DO BRASIL, 30 dez 1976, p. 15).

Ao receber os jornalistas para apresentar o balanço da DCDP, Rogério Nunes se mostrou agressivo em relação às críticas à Divisão de Censura, em duas situações. A primeira foi a afirmação de que os artistas que não apreciam a Censura são como doentes que não gostam de médico, uma comparação que promove a figura do censor ao status de guardião da moral para o bem da sociedade. Posteriormente, ele afirmou que os jornalistas não entendem a dinâmica da censura, pois acreditam que a função é vetar, quando, para ele, se tratava apenas de classificação etária, desconsiderando as críticas aos cortes e proibições relativos ao conteúdo das produções.

Em seguida, Nunes tratou da legislação referente à censura e apresentou comparações com o propósito de relativizar o controle exercido sobre os meios:

Em sua visão, o principal motivo para a atualização do decreto de 1946 foi a inclusão de normas relativas à televisão, veículo ainda inexistente à época, embora o decreto 
já mencione a TV. A modificação da legislação censória foi tema recorrente em todas as chefias do SCDP/DCDP, todavia nenhum ministro revogou o Decreto até a Constituição de 1988, que determinou o fim da censura. O diretor disse também que dispunha de um bom quadro de funcionários e apresentou o banco da DCDP, destacando que no ano de 1976 houve menos proibições que em 1975. (FERNANDES, 2018b, p. 226)

Pelo tratamento dado pela imprensa às ações da censura, na figura de Rogério Nunes, ressalta-se o papel do jornalismo na reprodução das versões oficiais, atuando como porta-voz do governo. Os jornais recorrem ao chamado "jornalismo declaratório" para pautar o tema em questão e apresentar uma única posição sobre o fenômeno descrito. Na perspectiva de Gaye Tuchman (2016), trata-se do "uso judicioso das aspas", que figura, ao lado de outras estratégias, para conferir credibilidade ao trabalho do jornalista. À medida que o uso das falas diretas demarca a opinião da fonte - no caso, o censor - , cria-se o efeito de retirar do jornalista a responsabilidade pelo conteúdo apresentado, ainda que seja possível observar com clareza o amplo espaço oferecido pelos jornais na época e a inexistência, nos jornais mencionados, de discursos contraditórios. Afinal, mesmo que o depoimento de Rogério Nunes apareça praticamente como uma resposta aos intelectuais, a estes não é concedido espaço de expressão na imprensa ao longo do período analisado.

\section{O debate público em torno da censura}

O oficialismo no tratamento da temática da censura foi o principal aspecto observado nos jornais dos anos 1970, o que revela um tipo de relação de controle e subserviência estabelecida entre o governo e os órgãos de imprensa. Contudo, alguns espaços de questionamento, resultantes do próprio contexto de fortalecimento dos movimentos de resistência e de defesa da liberdade de expressão, permitem entender o jornalismo, ainda que controlado pelo Estado, como um "campo polêmico" (MOUILLAUD, 2002) marcado pelas disputas de um contexto.

No que se refere à atuação dos agentes da ditadura, por exemplo, o lento processo de abertura política no final do mandato de Geisel, fez Rogério Nunes rever algumas posições censórias, como ele destaca na coletiva de dezembro de 1978. É importante lembrar que nessa época já havia sido revogado o Al-5 e que ocorria um forte movimento pela anistia, sancionada no ano seguinte. 
O diretor da Divisão de Censura e Diversões Públicas do Departamento de Polícia Federal, Rogério Nunes, disse ontem que a legislação a ser cumprida pela censura "impõe restrições de tal forma incoerentes com a moral vigente na moderna sociedade que o trabalho dos censores acaba se transformando numa constante batalha contra a realidade". Depois de reclamar a atualização da legislação sobre a censura, Rogério Nunes disse que "os atuais critérios carecem de uma abertura para as artes em geral, são extremamente subjetivos e até mesmo politicamente desastrosos". Disse Rogério Nunes que "o cinema, o teatro e a música, com suas mensagens quase sempre simbólicas, e de certa forma elitizadas, serão os grandes beneficiários da liberalização da censura", mas o mesmo processo não deverá ser aplicado ao rádio e à televisão. - Estes dois veículos de comunicação — disse - continuarão sob a vigilância mais severa dos censores, não apenas em matéria de política, mas também nos casos que dizem respeito à moral e aos bons costumes. (O GLOBO, 26 dez 1978, p. 5).

A opção por percorrer as entrevistas publicadas nos jornais teve como objetivo apurar algumas mudanças de opinião, próprias das tensões do contexto em pauta. Na entrevista, ao mesmo tempo em que Nunes reconhece a necessidade de reformulação da legislação censória, ele ainda busca justificar um caráter brando das práticas de controle às diversões públicas e atestar o cumprimento da lei por parte do DCDP. Já nesse momento, ele admite que foram cometidas injustiças por parte da censura e que o órgão estava disposto a rever decisões anteriores. Teatro, música e cinema seriam os grandes beneficiários desse novo pensamento de Nunes; todavia, a televisão e o rádio continuariam recebendo forte repressão. Essa entrevista causou polêmica entre a classe artística e os críticos, que repercutiram as declarações do diretor. Um exemplo pode ser conferido neste editorial do jornal O Globo, intitulado "Censura autocrítica".

Reconhece enfim o próprio Diretor da Divisão de Censura do Departamento de Polícia Federal, Rogério Nunes, que a atual legislação censória está distanciada dos padrões da moral vigente na sociedade moderna, donde o caráter anacrônico, irrealista e intolerante de muitas decisões daquele órgão. No caso das artes em geral, os critérios "extremamente subjetivos" dominam a mente e o trabaIho dos censores, levando-os a ver fantasmas ao meiodia em cada esquina. Para o Governo e para a imagem externa do Brasil, os resultados políticos desse obscurantismo intelectual e artístico têm sido "desastrosos". 
Poderia o Sr. Rogério Nunes citar numerosos exemplos de proibições estapafúrdias no campo do teatro, do cinema, da música, às vezes com o requinte de surgir o veto quando as peças teatrais e os filmes já se achavam liberados e a música já exaustivamente conhecida do público. Não devem ignorar os responsáveis por tais cincadas que só conseguiram aumentar a curiosidade e o interesse de grande parte do público em torno das obras postas no index, além de exercer-se por aí uma forma de protesto. Faltaria explicar apenas por que tanta certeza sobre as distorções da política de censura, a partir do órgão encarregado de administrá-lo, não levou o Departamento de Polícia Federal a promover oportunamente a renovação e correção dos parâmetros adotados, ainda hoje em fase de anteprojeto. Quanto à vigência mais severa dos censores para o rádio e a televisão, cuja manutenção o Sr. Rogério Nunes defende, parece evidente que o problema não constitui fato isolado no quadro de irrealismo e incoerência em que tem vivido a censura, mesmo antes da liberalização do regime. Também terá que sofrer as adaptações preconizadas pelo diretor da DCDP, na sua bem-vinda autocrítica. (O GLOBO, 27 dez 1978, p. 3).

Por se tratar de um texto que manifesta a voz do jornal sobre o tema, o tom crítico e as incoerências relativas à prática da censura são evidenciados. Este tipo de posicionamento, que ganha espaço apenas após o enfraquecimento do regime autoritário, contrasta com a prática do jornalismo declaratório observado nos textos anteriormente descritos sobre a censura praticada por Rogério Nunes.

O editorial refere-se aos pontos-chave do discurso de Nunes, quando reconhece que a censura está distanciada dos parâmetros morais da sociedade brasileira. Nunes já havia admitido problemas com a legislação em curso, que exigiam reformulações, todavia ele ainda afirmava que existia um "bom-senso" dos censores na análise das diversões públicas. Nessa última entrevista, o próprio diretor reconheceu que a falta de critérios fazia com que cada censor agisse de acordo com suas próprias impressões.

Em uma conferência proferida por Rogério Nunes no simpósio "Censura: histórico, situações e soluções", promovido pala Câmara dos Deputados no período de 16 de maio a 30 de agosto de $1979^{16}$, alguns aspectos sobre o funcionamento da censura são expostos. Nunes realizou a conferência

16 O simpósio foi presidido pelo deputado Israel Dias-Novais (MDB-SP), tinha a coordenação do deputado Paulo Pimentel (Arena-PR), sendo o deputado Albérico Cordeiro (Arena-AL) e a deputada Cristina Tavares (MDB-PE) os relatores. 
no dia 22 de maio de 1979; portanto, após deixar a direção da DCDP, enquanto atuava como Chefe do Gabinete Civil do governo. Ao se referir à participação do censor no evento, Fernandes (2018b) observa:

Durante a conferência, Nunes explicou a "mecânica" da censura à telenovela. Informou que a carência da legislação não previa a forma como as telenovelas deveriam ser censuradas e afirmou que existia um "acordo de cavaIheiros" entre a censura e as emissoras de TV. De acordo com Nunes, o primeiro passo era o envio da sinopse, com cerca de 10 a 12 páginas". (FERNANDES, 2018b, p. 228).

A sinopse, de acordo com Nunes, apresentava um relato "sucinto, dando a ideia global da história, das tramas, do que vai acontecer, enfim. Verificada essa sinopse, a Censura se pronunciava" (SIMPÓSIO..., 1980, p. 36).

Na sequência, a emissora iniciava a gravação e, posteriormente, enviava os dez primeiros capítulos gravados, acompanhados dos roteiros com as marcações: “Esses 10 capítulos são examinados e, naturalmente, não tendo maior comprometimento para aquele horário, são liberados os 10 primeiros episódios" (SIMPÓSIO..., 1980, p. 36). Os capítulos seguintes eram enviados em blocos, variando de um a quatro capítulos. Nunes ainda afirmou que as emissoras burlavam a censura, pois os primeiros capítulos obedeciam às normas censórias e os demais apresentavam impropriedades, não tendo como a censura realizar uma reclassificação:

[...] esses 10 capítulos vêm rigorosamente dentro das exigências censórias. Mas, com a novela colocada no ar, o autor começa a ser influenciado pela assistência e a empresa a sentir interesse em atrair o espectador, em ganhar Ibope. Agravam-se os problemas e a Censura fica impossibilitada de parar a novela. Por quê? Se alterar a impropriedade, se colocá-la num horário mais tarde, significa, praticamente, proibi-la, porque o horário seguinte está comprometido com outros patrocinadores, com outro espetáculo, e a empresa não tem como colocar dois espetáculos no mesmo horário. E se proibir desaba o mundo sobre a Censura, todo o público se volta contra a Censura porque proibiu um espetáculo já liberado. Então, fica tolhida para tomar qualquer providência. Multá-la com 10 centavos significa alguma coisa? Nada. Suspender o espetáculo promove-o, naturalmente. Aí está a grande dificuldade: uma legislação obsoleta que hoje praticamente nada significa para o referido meio de comunicação, já que não cogita a televisão. (SIMPÓSIO..., 1980, p. 36). 
A análise documental realizada por Fernandes (2018), ao verificar as telenovelas exibidas no período de 1968 a 1976, mostrou procedimentos diferentes daqueles relatados por Nunes. A Censura pressionava as emissoras a se adequarem às normas e, em algumas impropriedades, o chefe da DCDP concedia um prazo específico para as emissoras. Em diversos momentos, telenovelas foram encurtadas e personagens apresentaram grandes modificações. Nesse discurso, Nunes minimizou as práticas de controle sob seu comando, evidenciando a estrutura burocrática da pasta.

Em seguida Nunes apontou como deveria ser feita a censura da telenovela, reforçando argumentos já presentes nos jornais e seguindo a linha proposta anteriormente pelo ministro Falcão: “Para evitar os inconvenientes que sempre surgem seria indispensável tornar obrigatória a apresentação antecipada do texto integral da novela, para que a Censura sobre ele se manifeste, ficando a liberação condicionada ao exame da gravação" (SIMPÓSIO..., 1980, p. 36).

É importante lembrar que o debate sobre censura aqui delimitado diz respeito às questões de ordem moral, presentes nas falas de Rogério Nunes. Sabe-se, entretanto, que juntamente com a censura aos temas relativos a comportamentos e relacionamentos, representados nas diversões públicas, havia a censura político-ideológica, que atingiu tanto às produções culturais quanto ao conteúdo dos jornais. Estes últimos conviveram com práticas de controle e sofreram, em alguns casos, severas punições por publicar temas contrários à ordem estabelecida. Este aspecto revela as múltiplas faces da censura e o seu papel na legitimação do regime político ditatorial ${ }^{17}$.

\section{Considerações Finais}

O estudo concentrado nas ações de Rogério Nunes revelou algumas pistas sobre o modo como a censura esteve presente na pauta dos jornais e serviu como meio de sustentação do poder hegemônico. É uma vertente do que Smith (2000) já havia verificado e denominado como "acordo forçado". Para além dessa interpretação, percebemos a possibilidade de tecer o cotidiano, nesse caso o institucionalizado, por meio de excerto de matérias jornalísticas. Ao acompanhar o tempo presente da escrita da história, o jornalismo proporciona uma visão fragmentada sobre um todo, revelando possíveis mudanças de comportamento (nesse caso censório) em pequenos interstícios. Foi possível perceber que, ao longo do tempo, as práticas e discursos 
de Nunes sobre a censura sofreram modificações, embora a mentalidade ideológica tenha se mantido a mesma. A particularidade foi voltada especificamente para a televisão como veículo massivo, sob a tutela do Estado, entendido como o guardião da moral e dos bons costumes.

Como recorremos aos dirigentes, também se mostra necessário pensar o "dito" e o "não dito", em função do próprio cargo e das relações estabelecidas com os veículos. Embora existam traços claros da expressão da mentalidade censória em nível individual, a parte corporativa/governamental inevitavelmente também se fazia presente, além da política censória expressa por cada um dos generais presidentes e do que era possível declarar aos jornalistas.

Especificamente em relação a Rogério Nunes, é sensível à modificação das ações com o passar dos anos - mantendo a mesma estrutura de longa duração em termos de mentalidade. Se no primeiro momento, o dirigente se portava como defensor das práticas censórias positivistas, burocráticas, estritamente legais, posteriormente chegou a afirmar publicamente a existência de falhas nesse processo, admitindo a necessidade de realizar revisões em âmbito burocrático, mas não ideológico. Tal mudança, provavelmente, ocorreu em razão do próprio cenário político, diante do crescimento de uma opinião pública favorável à liberdade de expressão e desejosa de aspirações democráticas.

A análise do papel ocupado pelo censor e suas manifestações públicas em defesa da função de fiscalizador moral do país, amplamente repercutido na imprensa do período, foi realizada com o propósito de observar como a censura foi tematizada pelo jornalismo de referência, que era também alvo de censura e controle governamental. Ao interpretar as lógicas e disputas presentes no interior dos discursos, são evidenciados aspectos sobre as relações de aliança e/ou de contraposição que envolvem o censor, as empresas de mídia e o regime político vigente. Revela-se ainda que os rastros permanecem na longa duração e são evocados como legitimadores do discurso. O artigo contribuiu para estabelecer uma narrativa possível da gestão de Rogério Nunes à frente da censura de diversões públicas federalizada.

Guilherme Moreira Fernandes é professor do Centro de Artes, Humanidades e Letras da Universidade Federal do Recôncavo da Bahia e do Programa de Pósgraduação em Comunicação da UFRB. É presidente da Rede Folkcom (gestão 2019/2021). Realizou estágio pós- 
doutoral no Programa de Pós-graduação em Jornalismo da Universidade Estadual de Ponta Grossa

guilherme.fernandes@ufrb.edu.br.

Karina Janz Woitowicz é professora Dra. do Curso de Jornalismo e do Programa de Pós-Graduação em Jornalismo da Universidade Estadual de Ponta Grossa. É pós-doutora em Comunicação pelo Centro Internacional de Estudios Superiores de Comunicación para América Latina (CIESPAL).

karinajw@gmail.com

Contribuições de cada autor: Guilherme: fundamentação teórica e conceituação, primeira redação, investigação de campo, metodologia e análise formal do corpus; Karina: escrita, revisão e edição.

\section{Referências}

AQUINO, M. A. Censura, Imprensa, Estado Autoritário (1968-1978). Bauru: Edusc, 1999.

BARBOSA, M. História Cultural da Imprensa: Brasil - 1800-1900. Rio de Janeiro: Mauad X, 2010.

Percursos do olhar. Niterói: UFF, 2007.

CARNEIRO, M. L. T. (org.). Minorias Silenciadas. São Paulo: Edusp, 2002.

FERNANDES, G. M. Mentalidade Censória e Telenovela na Ditadura Militar. 2018. $439 \mathrm{f}$. Tese (Doutorado em Comunicação e Cultura) - Programa de Pós-graduação em Comunicação, Escola de Comunicação, Universidade Federal do Rio de Janeiro, Rio de Janeiro, 2018.

. A Mentalidade Censória de Rogério Nunes expressa nos Jornais Impressos. In: XXI Seminário de Inverno de Estudos em Comunicação, 21, 2018. Anais [...]. Ponta Grossa: UEPG, 2018b. Disponível em: <https://sites.uepg.br/jornalismo/ocs/index.php/seminariodeinverno/artigos/paper/viewFile/8/1>. Acessado em: 10/04/2021.

A Censura Contra a Cultura Popular/Marginal: A Mentalidade Censória na Era Rogério Nunes (1971-1979). In: XIX Conferência Brasileira de Folkcomunicação, 19, 2018. Anais [...]. Parintins: UFAM, 2018c. Disponível em: <https://doity.com.br/media/doity/ submissoes/artigo-396f0327b40a8e66f9ac7c59268e70f43fa31105-arquivo.pdf>. Acessado em: 10/04/2021. 
Censura às diversões públicas: a mentalidade censória de Armando Falcão. In: XII Encontro Nacional de História da Mídia. Anais [...]. Natal: UFRN, 2019. Disponível em: <http:// www.ufrgs.br/alcar/encontros-nacionais-1/encontros-nacionais/12o-encontro-2019/ gt-historia-das-midias-audiovisuais/censura-as-diversoes-publicas-a-mentalidade-censoria-de-armando-falcao/view>. Acessado em: 10/04/2021.

FOUCAULT, M. História da Sexualidade. Vol. 2: O uso dos prazeres. Rio de Janeiro: Graal, 1984.

LE GOFF, J. As mentalidades: uma história ambígua. In: LE GOFF, Jacques; NORA, Pierre (org.). História: novos objetos. $3^{\text {a }}$ ed. Rio de Janeiro: Francisco Alves, 1988. p. 68-83.

MARCONI, P. A censura política na imprensa brasileira. 2a ed. São Paulo: Global, 1980.

MARTINS, A. L. Sob o signo da censura. In: CARNEIRO, Maria Luiza T. (org.). Minorias Silenciadas. São Paulo: Edusp, 2002. p. 155-179.

MATTOS, S. História da televisão brasileira. 5ª ed. Petrópolis: Vozes, 2010.

MOUILLAUD, M. Da forma ao sentido. In: MOUILLAUD, Maurice; PORTO, Sérgio Dayrell (orgs.). O jornal: da forma ao sentido. $2^{\text {a }}$ ed. Brasília: Ed. UNB, 2002. p. 29-38.

MOREIRA, S. V. Análise Documental. In: DUARTE, J.; BARROS, A. Métodos e técnicas de pesquisa em Comunicação. $2^{a}$ ed. São Paulo: Atlas, 2006.

PARK, R. A notícia como forma de conhecimento: um capítulo da Sociologia do Conhecimento. In: STEINBERG, Charles S. (org.). Meios de Comunicação de Massa. São Paulo: Cultrix, 1970. p. 168-185.

SMITH, A. M. Um acordo forçado. Rio de Janeiro: FGV, 2000.

TUCHMAN, G. A objetividade como ritual estratégico: uma análise das noções de objetividade dos jornalistas. In: TRAQUINA, Nelson (org). Jornalismo: questões, teorias e “estórias". Florianópolis: Insular, 2016. p. 111-132.

VOVELLE, M. Ideologias e Mentalidades. 2a Ed. São Paulo: Brasiliense, 1991. Fontes Documentos Primários

BARRETO FILHO, M. Diversões Públicas. Rio de Janeiro: A. Coelho Branco Filho, 1941.

CENSURA AUTOCRÍTICA. O Globo, Editorial. Rio de Janeiro, Ano 54, Edição nº 16508, 27 dez 1978. p. 3.

DIRETOR DA CENSURA ACHA LEI INCOERENTE COM A REALIDADE. O Globo, Primeiro Caderno, O País. Rio de Janeiro, Ano 54, Edição n 16507, 26 dez 1978. p. 5.

DIRETOR DA CENSURA VÊ INTELECTUAL COMO DOENTE QUE 'DETESTA MÉDICOS'. Jornal do Brasil, $1^{\circ}$ Cad. Rio de Janeiro, Ano 86, Edição n 265, 30 dez 1976. p. 15.

FAGUNDES, C. Censura e liberdade de expressão. São Paulo: Record, 1974. 
POLICIAL DE CARREIRA VAI PARA CENSURA. Jornal do Brasil, $1^{\circ} \mathrm{Cad}$. Rio de Janeiro, Ano 81, Edição n 170, 23 out 1971. p. 3.

PROGRAMAS DE TELEVISÃO EXIGEM RIGOR NO EXAME. Jornal do Brasil, $1^{\circ}$ Cad. Rio de Janeiro, Ano 85, Edição n 142, 28 ago 1975. p. 14.

ReCORde dA CEnSuRA. Diário de Pernambuco, Segundo Caderno. Recife, Ano 150, Edição n 233, 30 ago 1975. p. 9.

SIMPÓSIO “CENSURA: HISTÓRICO, SITUAÇÃO E SOLUÇÃO”. Diário do Congresso Nacional. Seção I. Ano 35, Suplemento ao n 154. Brasília, 3 dez. 1980.

Artigo recebido em 13/05/2020 e aprovado em 24/12/2020. 